\title{
Analisis Fase Preliminary Strategis Sistem Informasi dalam Pengembangan Smart Campus
}

\author{
Cholid Fauzi", Beri Noviansyah \\ Teknik Informatika, Politeknik Negeri Bandung, Bandung, Indonesia \\ Email: 1,*cholid.fauzi@polban.ac.id, ${ }^{2}$ beri.noviansyah@polban.ac.id \\ Email Penulis Korespondensi: cholid.fauzi@polban.ac.id \\ Submitted: 10/12/2021; Accepted: 25/12/2021; Published: 31/12/2021
}

\begin{abstract}
Abstrak-Smart Campus mengacu pada integrasi dari kesatuan kehidupan kampus yang ditunjang dengan teknologi. Penerapan Smart Campus merupakan perkembangan dari pengelolaan yang bersifat konvensional menjadi kampus yang menerapkan teknologi salah satunya sistem informasi. Sistem informasi agar dapat berhasil dan optimal, diperlukan perencanaan strategis sistem informasi (SISP) yang efektif dengan bisnis proses dari organisasi dan dijadikan sebagai cetak biru bagian dari IT Masterplan untuk implementasi Smart Campus tersebut. Perencanaan Strategis Smart Campus yang diimplementasikan dengan memanfaatkan kerangka Ward and Peppard, dengan identifikasi kebutuhan sistem informasi berdasarkan Criticat Success Factor (CSF), Value Chain, Analisis Kesenjangan dan McFarlan Portfolio. Penelitian ini menghasilkan informasi bagi para pemangku keputusan dalam membuat kebijakan kampus dalam mengimplementasikan berbagai layanan yang disediakan sistem informasi sebagai bagian dari Smart Campus yang dapat digambarkan sebagai kampus yang secara cerdas berinteraksi dengan para sivitas akademikanya.
\end{abstract}

Kata Kunci: SISP; CSF; Value Chain; McFarlan Portfolio; Strategi Sistem Informasi; USG

\begin{abstract}
Smart Campus refers to the integration of the unity of campus life that is supported by technology. The application of Smart Campus is a development from conventional management campus to campus that applies technology, one of the technologies is an information system. For an information system to be successful and optimal, an appropriate strategic information system (SISP) planning is needed in accordance with the business processes of the institution and is used as a blueprint as part of the IT Masterplan for the implementation of the Smart Campus. Smart Campus Strategic Planning implemented by utilizing the Ward and Peppard framework, with identification of information system needs based on the Critical Success Factor (CSF), Value Chain, Gap Analysis and McFarlan Portfolio. The results of this study can be used as a consideration for decision makers to determine campus policies in implementing various services provided by information systems as part of the Smart Campus, which can be described as a campus that intelligently interacts with its academics.
\end{abstract}

Keywords: SISP; CSF; Value Chain; McFarlan Portfolio; Information System Strategy

\section{PENDAHULUAN}

Kampus yang menerapkan teknologi informasi, walaupun dalam implementasinya tidak mudah dikarenakan melibatkan banyak sarana yang harus terwujud, salah satu komponen nya ada sistem informasi[1]. Informasi dari penerapan SI yang tidak direncanakan dan diimplementasikan dengan baik tidak akan dapat digunakan oleh level eksekutif. Sehingga yang sering ditanyakan oleh pengambil keputusan apakah SI yang diimplementasikan mampu meberikan informasi yang riil terhadap organisasi. Smart Campus mengacu pada integrasi dari kesatuan kehidupan kampus yang ditunjang dengan teknologi. Penerapan Smart Campus merupakan perkembangan dari pengelolaan yang bersifat konvensional menjadi kampus yang menerapkan teknologi, walaupun dalam implementasinya tidak mudah dikarenakan melibatkan banyak sarana yang harus terwujud[2]. Berbagai peneliti yang membangun Smart Campus menyampaikan definisi Smart Campus berdasarkan pendekatan yang berbeda. Jika dikelompokkan, maka ada 3 pendekatan yakni: berbasis teknologi, mengadopsi konsep smart city, dan berdasarkan dari bisnis proses organisasi [4].

Tujuan utama dari Smart Campus adalah mempermudah seluruh kegiatan sivitas akademika[5]. Penelitian ini diharapkan dapat membuat model perencanaan strategis Smart Campus sesuai dengan visi misi organisasi yang diharapkan. Agar implementasi Smart Campus dengan penggunaan sistem informasi ini dapat berhasil dan optimal, diperlukan perencanaan strategis sistem informasi (SISP) yang tepat sesuai dengan bisnis proses dari institusi dan dijadikan sebagai cetak biru bagian dari IT Masterplan untuk implementasi Smart Campus tersebut[2]. Model ini akan dirumuskan berdasarkan analisis organisasi dan hasil kajian literatur mengenai perencanaan strategis SI yang relevan termasuk perencanaan Smart Campus yang akan diimplementasikan dengan memanfaatkan kerangka Ward and Peppard, Critical Success Factor (CSF) dan Value Chain[3].

Metode yang dilakukan dalam penelitian ini adalah pengambilan data secara wawancara, obervasi lapangan kondisi eksisting dan rancangan survey, studi literatur, penyebaran kuesioner, analisis data awal dan lanjut, dan pengambilan kesimpulan empiris. Penelitian ini bertujuan untuk membuat preliminary analisis dalam perencanaan strategis Smart Campus dengan kekhususan dalam sistem informasi sesuai topik roadmap topik penelitian yaitu literasi state of the art dalam IT Masterplan. Luaran dari penelitian ini yaitu analisis perencanaan strategis SI yang dirumuskan hasil analisis organisasi dan hasil kajian literatur mengenai perencanaan strategis SI yang relevan termasuk perencanaan Strategis Smart Campus yang diimplementasikan dengan memanfaatkan kerangka Ward and Peppard, dengan identifikasi kebutuhan sistem informasi berdasarkan Critical Success Factor (CSF), Value Chain, Analisis Kesenjangan dan McFarlan Portfolio. Penelitian ini sangat dibutuhkan oleh Politeknik Negeri Bandung untuk mempersiapkan draft rekomendasi IT Masterplan untuk mengimplementasikan Smart Campus. Hasil dari penelitian 
ini dapat dijadikan pertimbangan bagi para pemangku keputusan untuk menentukan kebijakan kampus dalam mengimplementasikan berbagai layanan yang disediakan sistem informasi sebagai bagian dari Smart Campus yang dapat digambarkan sebagai kampus yang secara cerdas berinteraksi dengan para sivitas akademikanya[5]. Penelitian ini bertujuan untuk membuat analisis dalam perencanaan strategis sistem informasi Smart Campus sesuai dengan visi misi organisasi yang diharapkan. perencanaan strategis SI ini akan dirumuskan berdasarkan hasil analisis organisasi dan hasil kajian literatur mengenai perencanaan srategis SI yang relevan termasuk perencanaan Smart Campus yang akan diimplementasikan dengan memanfaatkan kerangka Ward and Peppard, dengan identifikasi kebutuhan sistem informasi berdasarkan Critical Succes Factors (CSF), Value Chain, Gap Analysis (Analisis Kesenjangan) dan McFarlan Portfolio. Penelitian ini sangat dibutuhkan oleh Politeknik Negeri Bandung untuk mempersiapkan kuesioner dan pilot dalam perencanaan strategis untuk mengimplementasikan Smart Campus.

Harapan perencanaan dan strategi penerapan sistem informasi Smart Campus dapat berjalan dengan efektif. Hasil dari penelitian ini dapat dijadikan pertimbangan bagi para pemangku keputusan untuk menentukan kebijakan kampus dalam mengimplementasikan berbagai layanan yang disediakan sistem informasi.

\section{METODOLOGI PENELITIAN}

\subsection{Tahapan Studi Literatur}

\subsubsection{Sistem Information Strategic Planning}

Perencanaan strategi sistem informasi adalah sistem-sistem komputer yang berada dalam level organisasi yang mngubah tujuan, operasi-operasi, produk dan jasa, atau hubungan lingkungan untuk membantu organisasi mencapai keunggulan kompetitif[9]. Perencanaan strategis SI/TI adalah proses mengidentifikasi portfolio dari aplikasi SI di organisasi yang mendukung pelaksanaan rencana bisnis dan merealisasikan tujuan bisnisnya. Perencanaan strategis inijuga menjelaskan berbagai alat, teknik, dan memberikan kerangka kerja untuk organisasi khusunya manajemen level atas untuk menyelaraskan strategi SI dengan strategi bisnis, ataupun mencari kesempatan yang baik melalui penerapan teknologi yang inovatif [4][10]. Menurut Ward and Peppard, Sebuah organisasi membutuhkan perencanaan strategi SI karena berbagai alasan antara lain:

a) Hasil dalam perencanaan strategi terkait SI ini dapat digunakan sebagai bahan diskusi antara manajemen dan unit maupun divisi SI untuk menyamakan persepsi dengan strategi mereka tentang cara terbaik untuk menggunakan sumber daya informasi yang mereka miliki.

b) Mengkomunikasikan rencana kedepan / future state perusahaan kepada pihak lain dan membantu pihak manajemen dan ahli system informasi dalam membuat keputusan mendasar terkait dengan bagaimana alur informasi ini akan diarahkan untuk membantu bisnis organisasi.

c) Membantu unit dalam merencanakan alokasi sumber daya yang dimiliki perusahaan untuk mengembangkan SI yang penting dan bermanfaat bagi bisnis organisasi termasuk anggaran yang harus disediakan untuk pengembangan SI ersebut.

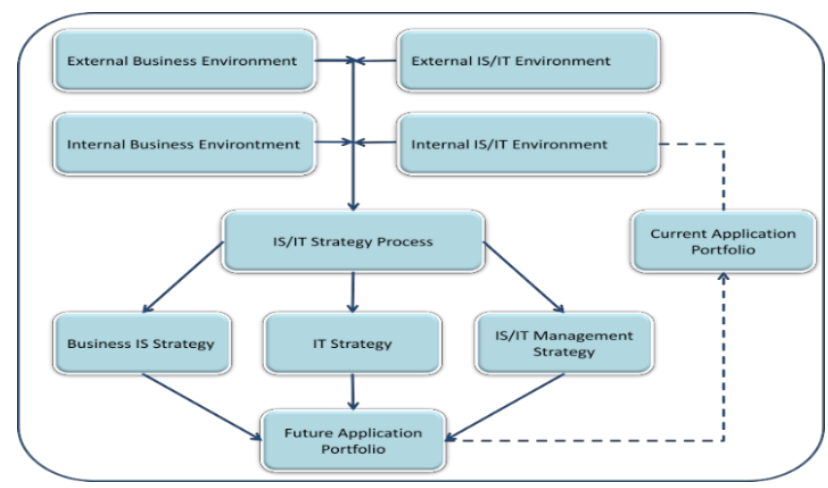

Gambar 1. Model Strategis SI/TI Ward dan Peppard[6]

Metodologi perencanaan strategis system informasi menurut Ward dan Peppard terdiri dari beberapa tahapan masukan (input) dan tahapan keluaran (output). Tahapan masukan (input) terdiri dari:

a) Analisis lingkungan bisnis internal: Melingkupi dari aspek-aspek strategi saat ini, sasaran, sumber daya, proses, serta budaya nilai-nilai bisnis organisasi.

b) Analisis lingkungan bisnis external: Melingkupi aspek-aspek dari politik, industri, ekonomi, maupun iklim bersaing perusahaan.

c) Analisis lingkungan sistem informasi dan teknologi informasi internal.: Melingkupi kondisi eksisting sistem informasi dan teknologi informasi organisasi dari perspektif bisnis saat ini, kontribusi terhadap bisnis, kematangannya (maturity), sumber daya, infrastruktur teknologi, keterampilan sumber daya manusia, termasuk portofolio dari sistem informasi dan teknologi informasi yang ada saat ini. 
d) Analisis lingkungan sistem informasi dan teknologi informasi external:. Mencakup teknologi dan peluang pemanfaatannya, serta penggunaan sistem informasi dan teknologi informasi pesaing, pelanggan dan pemasok. Sedangkan tahapan keluaran (output) merupakan tahapan yang sudah dilakukan.

\subsubsection{Critical Success Factor}

Critical Success Factor atau disebut CSF merupakan sebuah metode dalam melakukan analisis dengan mempertimbangkan hal apa saja yang dipandang kritis di dalam lingkungan perusahaan. Kritis dalam hal ini adalah mendefinisikan faktor-faktor apa saja yang mempengaruhi keberhasilan dan kesuksesan perusahaan atau organisasi dan dapat ditentukan jika objektif organisasi telah diidentifikasi[7]. CSF bisa memberikan gambaran pada organisasi tentang aspek maupun faktor kritis apa saja di setiap aktivitas. Selain itu juga, proses bisnis perusahaan yang mempengaruhi kinerja perusahaan dalam mencapai visi dan misi serta keberhasilan bisnisnya. Tujuan dari CSF adalah menggambarkan objektif secara lebih jelas dalam menentukan aktivitas yang harus dilakukan dan informasi apa yang dibutuhkan[8]

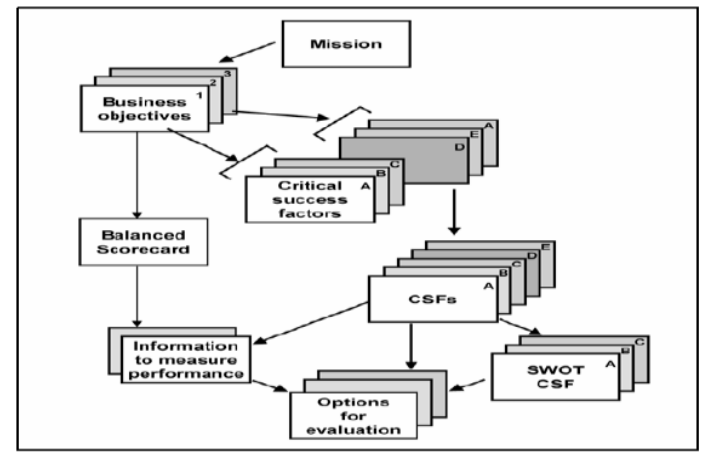

Gambar 2. Critical Success Factor

Analisis CSF dalam perencanaan sistem informasi menurut Ward and Peppard, menjelaskan sebagai berikut:

a) Analisis CSF merupakan teknik yang paling efektif dalam melibatkan manajemen senior alam mengembangkan strategi sistem informasi. CSF secara keseluruhan telah berdasarkan pada bisnis dan memberikan komitmen bagi manajemen puncak dalam menggunakan sistem informasi, yang diselaraskan dengan pencapaian tujuan perusahaan melalui area bisnis yang kritis.

b) Analisis CSF menghubungkan proyek sistem informasi yang akan diiimplementasikan dengan tujuannya, dengan demikian sistem informasi nantinya akan dapat direalisasikan agar sejalan dengan strategi bisnis perusahaan.

c) Analisis CSF juga dapat menjadi perantara yang baik dalam mengetahui informasi apa yang diperlukan oleh setiap individu.

d) Analisis CSF menyediakan suatu hubungan antara kebutuhan dengan informasi dan memegang peranan penting dalam memprioritaskan investasi modal yang potensial.

e) Analisis CSF sangat berguna dalam perencanaan sistem informasi pada saat strategi bisnis tidak berjalan sesuai dengan tujuan perusahaan, dengan memfokuskan pada masalah-masalah tertentu yang paling kritis.

f) Analisis CSF apabila digunakan sejalan dengan analisis value chain dalam mengidentifikasi proses yang paling kritis, serta memberikan fokus pada pencapaian tujuan melalui kegiatan-kegiatan yang paling tepat untuk dilaksanakan

\subsubsection{PEST}

Analisis PEST merupakan suatu cara atau alat yang bermanfaat untuk meringkas lingkungan eksternal dalam operasi bisnis. PEST memberikan pertimbangan bahwa bisnis harus menghadapi pengaruh dari lingkungan politik, ekonomi, sosial, dan teknologi. Analisis PEST mencakup kondisi lingkungan makro, yaitu perekonomian, teknologi, politik dan hukum, dan sosiokultural. Analisis PEST terkait dengan pengaruh lingkungan pada suatu bisnis[9].

a) Politik: Faktor-faktor politik dan bisa juga peraturan yang menjadi dasar dalam yang menjadi pengaruh dalam menentukan kebijakan institusi.

b) Ekonomi: Perubahan politik juga mempengaruhi perubahan ekonomi. Keadaan perekonomian pada waktu sekarang dan di masa yang akan datang dapat mempengaruhi kemajuan dan strategi perusahaan. Setiap segi ekonomi ini dapat membantu atau menghambat usaha mencapai tujuan perusahaan dan menyebabkan keberhasilan ataupun kegagalan strategi.

c) Sosial:Faktor-faktor sosial terdapat dalam penilaian dari sikap konsumen dan karyawan yang mempengaruhi strategi. Para perencana strategi harus mengikuti perubahan pada tingkatan pendidikan dan penilaian sosial dengan maksud menilai dampaknya terhadap strategi perusahaan.

d) Teknologi: Perencanaan strategi organisasi yang efektif adalah dengan memeriksa lingkungan dan mencari perubahan teknologi yang dapat menunjang perusahaan dalam mencapai tujuan bisnisnya, karena perubahan teknologi dapat memberikan peluang besar untuk meningkatkan hasil, tujuan atau mengancam kedudukan 
perusahaan. Kemauan untuk melakukan inovasi dan mengambil risiko nampak merupakan komponen yang penting.

\subsubsection{Value Chain}

Analisis value chain adalah kegiatan menganalsis kumpulan aktivitas yang dilakukan untuk merancang, memproduksi, memasarkan mengantarkan dan mendukung produk atau jasa [5]. Pendekatan value chain dibedakan menjadi dua tipe aktivitas bisnis, yaitu aktivitas utama (primary activities) dan aktivitas pendukung (support activities).

a) Aktivitas utama (Primary activities): Aktivitas-aktivitas utama pada perusahaan yang pada akhirnya memberikan kepuasan pada pelanggan. Aktivitas-aktivitas tersebut tidak hanya dilakukan dengan baik, tapi juga harus saling berhubungan dengan efektif jika keseluruhan performa bisnis hendak dioptimalkan. Aktivitas utama terdiri dari inbound logistics, outbound logistics, sales and marketing, serta services.

b) Aktivitas pendukung (Support activities): Aktivitas - aktivitas yang melengkapi aktivitas utama dengan berbagai fungsi, yaitu kelengkapan infrastruktur, manajemen sumber daya manusia, pengadaan barang, dan pengembangan teknologi.

Teknologi informasi merupakan alat yang potensial untuk digunakan dalam menciptakan atau menambah nilai nilai dan teknologi informasi dimaksudkan untuk melihat sampai sejauh mana peran sistem dan teknologi informasi di perusahaan saat ini di rantai nilai[11]. Dari analisis ini dapat diketahui dan dijawab pertanyaanpertanyaan berikut ini:

1) Dari kegiatan-kegiatan mana saja sistem informasi sudah mempunyai peran dalam menciptakan atau menambah nilai di rantai nilai?

2) Apakah peran sistem informasi sudah optimal atau masih dapat ditingkatkan di kegiatan-kegiatan yang sudah memanfaatkannya?

3) Di kegiatan-kegiatan mana saja sistem informasi masih belum berperan menciptakan atau menambah nilai di rantai nilai?

4) Apakah sistem informasi dapat diterapkan di kegiatan-kegiatan yang belum memanfaatkannya? Berdasarkan dokumen perusahaan yang menyebutkan tugas dan fungsi setiap unit kerja serta pengamatan yang dilakukan terhadap proses kerja yang terjadi di masing-masing unit kerja, secara diagram, value chain dapat terlihat seperti gambar di bawah ini.

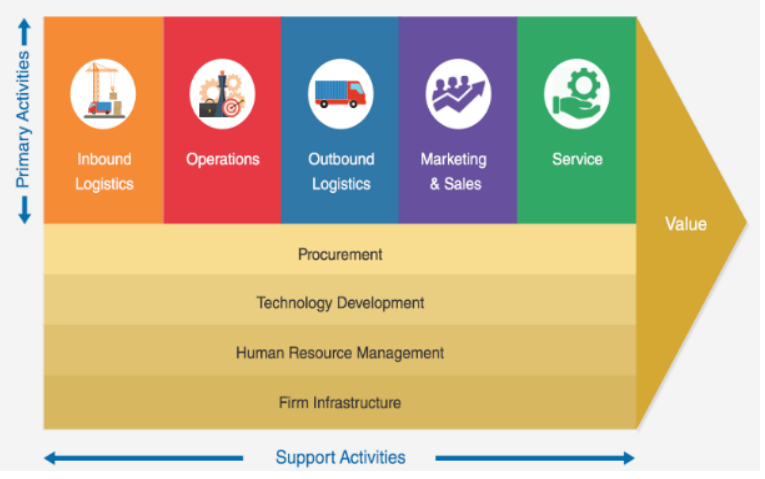

Gambar 3. Value Chain

\subsubsection{Analisis Kesenjangan}

Analisis kesenjangan merupakan salah satu alat yang dapat digunakan untuk mengevaluasi kinerja karyawan. Gap analysis atau analisis kesenjangan juga merupakan langkah yang sangat penting dalam melakukan tahapan perencanaan ataupun tahap evaluasi kerja. Metode ini meupakan metode yang paling umum digunakan dalam pengelolaan manajemen internal suatu lembaga. Secara harfiah "gap" mengidentifikasikan adanya suatu perbedaan antara satu hal dengan hal lainnya. Gap analysis sering digunakan di bidang manajemen dan menjadi salah satu alat yang digunakan untuk mengukur kualitas pelayanan (quality of service). Secara singkat, gap analysis bermanfaat untuk:

a) Menilai seberapa besar kesenjangan antara kinerja aktual dengan suatu standar kerja yang diharapkan

b) Mengetahui peningkatan kinera yang diperlukan untuk menutup kesenjangan tersebut, dan

c) Menjadi salah satu dasar pengambilan keputusan terkait prioritas dan biaya yang dibutuhkan untuk memenuhi standar pelayanan yang telah ditetapkan.

\subsubsection{McFarlan Portfolio}

Portofolio McFarlan digunakan untuk memetakan aplikasi sistem informasi berdasarkan kontribusinya terhadap perusahaan. Pemetaan dilakukan pada empat kuadran (strategic, high potential, key operation, and support)[13]. Dari hasil pemetaan tersebut didapatkan gambaran konstribusi sebuah aplikasi sistem informasi terhadap perusahaan dan pengembangan di masa mendatang, keempat kuadran tersebut dapat dilihat pada gambar di bawah ini. 


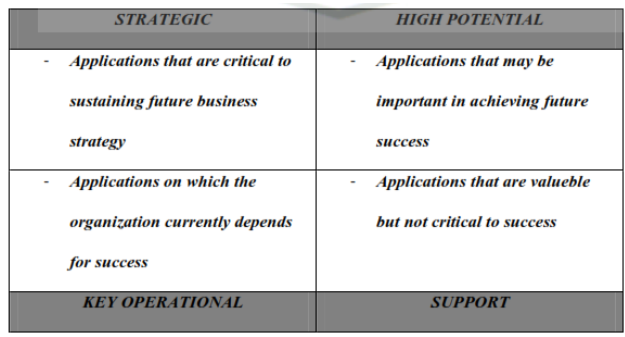

Gambar 4. McFarlan Portfolio

Portofolio McFarlan memiliki 4 (empat) kuadran, yaitu:

1. Application high potential: Merupakan aplikasi yang diperkirakan akan mempunyai potensi tinggi bagi perusahaan di masa mendatang namun masih dalam tahap penjajakan dan belum digunakan

2. Application strategic: Aplikasi yang bersifat kritis bagi perusahaan dan digunakan sebagi alat untuk mencapai tujuan utama agar perusahaan tersebut bertahan selama mungkin.

3. Application key operational: Aplikasi yang dapat dikategorikan penting agar perusahaan dapat terus beroperasi dan terus berjalan.

4. Application support: Aplikasi yang bernilai cukup penting tetapi tidak terlalu mendukung suksesnya perusahaan secara langsung.

\subsection{Metode Penelitian}

Tahapan selanjutnya dalam penelitian ini membutuhkan data dan informasi yang relatif sudah ada yang berkaitan dengan SISP, salah satu nya ada IT Masterplan sebelumnya dan Renstra Polban 2020-2024 sebagai bahan yang dapat mendukung kebenaran materi uraian pembahasan dari kerangka Ward dan Peppard yang dirujuk. Oleh karena itu, terlebih dahulu dilakukan studi literatur penelitian untuk mendapatkan data-data atau bahan yang diperlukan dan dibentuk kerangka berfikir menurut Ward and Peppard.

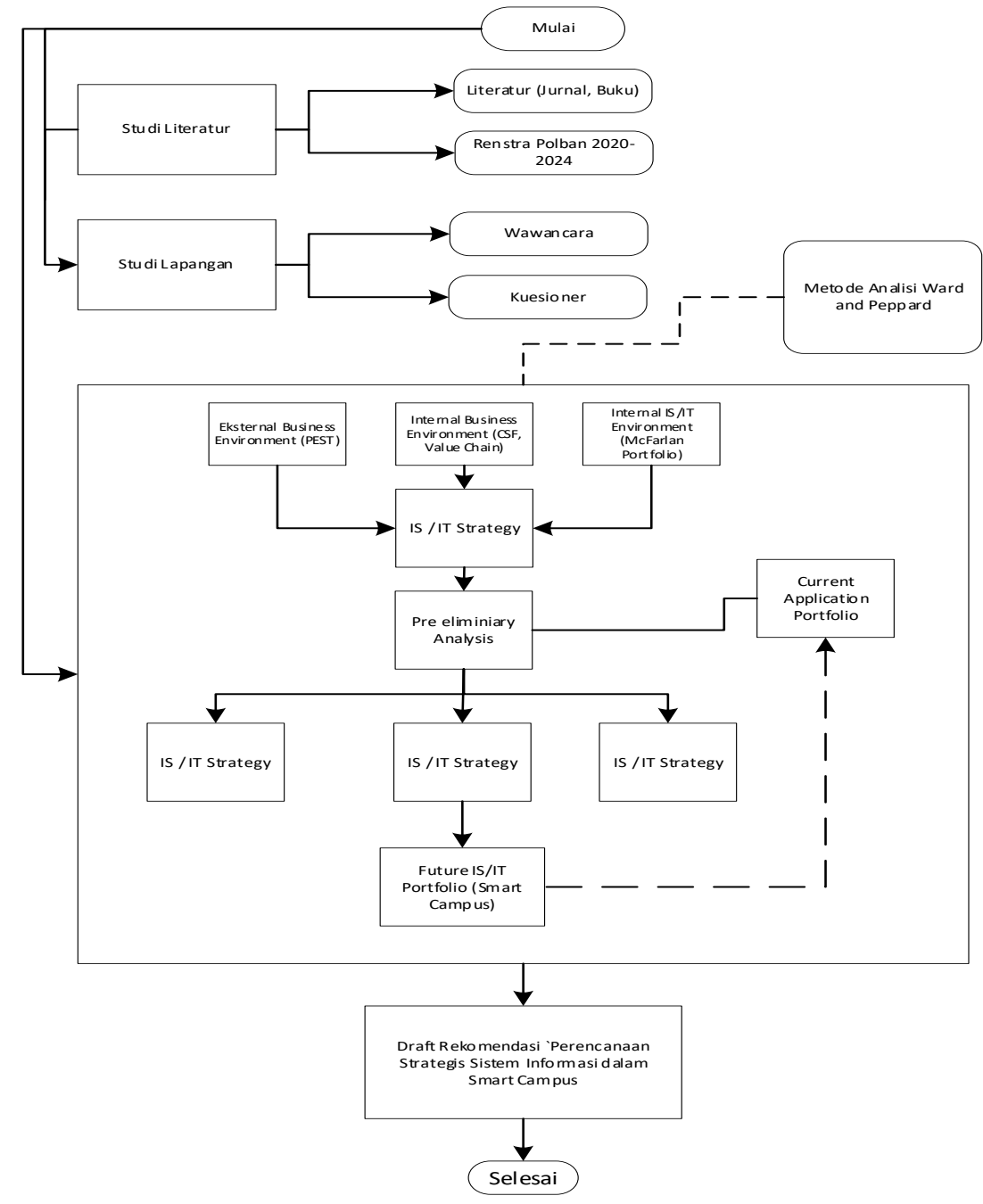

Gambar 5. Metodologi Penelitian 
Building of Informatics, Technology and Science (BITS)

Volume 3, No 3, December 2021, Page 130-140

ISSN 2684-8910 (media cetak)

ISSN 2685-3310 (media online)

DOI 10.47065/bits.v3i3.1013

Penjelasan dari kerangka berfikir penelitian ini (metode dan keluaran setiap tahapan penelitian) dapat dilihat pada Tabel 1.

Tabel 1. Detail Kerangka berfikir dan tahapan Penelitian

\begin{tabular}{|c|c|c|}
\hline Tahapan & Metode / Tools & Keluaran / Output \\
\hline Studi Literatur & $\begin{array}{l}\text { Wawancara dan observasi riil di } \\
\text { lingkungan Polban dalam hal in } \\
\text { Membaca literatur baik secara } \\
\text { konvensional maupun online }\end{array}$ & $\begin{array}{l}\text { Literatur dan studi kasus tentang SISP dalam implementasi } \\
\text { Smart Campus, terutama studi kerangka Pepprad and Ward, } \\
\text { Critical Success Factor, IT Value Chain, Gap Analysisi dan } \\
\text { McFarlan Portfolio }\end{array}$ \\
\hline Pengambilan data & $\begin{array}{l}\text { Wawancara dan observasi riil di } \\
\text { lingkungan Polban untuk memetakan } \\
\text { sistem informasi yang menjadi prioritas } \\
\text { dalam hal ini yang akang dikembangkan } \\
\text { oleh unit PSI }\end{array}$ & Kondisi bisnis dan SI/TI \\
\hline Pembuatan dan & Observasi lapangan dan pembuatan & Kondisi bisnis dan SI saat ini dan apa yang diharapkan dari \\
\hline Penyebaran & kuesioner ke stakeholder (Unit PSI, & Smart Campus dan Pemetaan Kuesioner dipetakan ke dalam \\
\hline Kuesionar & $\begin{array}{l}\text { Dosen dan Mahasiswa) Smart Campus } \\
\text { dari kerangka framework dari literature }\end{array}$ & kerangka yang sudah diteiliti. \\
\hline \multirow[t]{3}{*}{$\begin{array}{l}\text { Internal Business } \\
\text { Environment dan } \\
\text { IS/IT }\end{array}$} & Analisis Critical Success Factor & $\begin{array}{l}\text { Hasil analisa berdasarkan kerangka CSF: dilihat dari } \\
\text { berdasarkan tujuan utama dan indicator yang menjadikan } \\
\text { indicator tersebut berhasil atau tidak berdasarkan ukutan } \\
\text { yang sudah disepakati }\end{array}$ \\
\hline & Analisis value chain & $\begin{array}{l}\text { Hasil analisa dari identifikasi kebutuhan dan proses bisnis } \\
\text { utama dan pendukung dalam implemntasi Smart Campus }\end{array}$ \\
\hline & McFarlan Portfolio & $\begin{array}{l}\text { Hasil pemetaan komponen SI yang dibutuhkan di setiap unit } \\
\text { bisnis dengan kondisi saat ini beserta strateginya dalam }\end{array}$ \\
\hline $\begin{array}{l}\text { Preleiminary } \\
\text { Analysis }\end{array}$ & Gap analysis & $\begin{array}{l}\text { Hasil pemetaan komponen SI yang } \\
\text { dibutuhkan di setiap unit bisnis ke dalam } 4 \text { kuadran } \\
\text { McFarlan portfolio untuk future state. }\end{array}$ \\
\hline $\begin{array}{l}\text { Pembuatan } \\
\text { Rekomendasi } \\
\text { draft perencanaan } \\
\text { strategis SI dalam } \\
\text { Smart Campus }\end{array}$ & & $\begin{array}{l}\text { Draft kuesioner dan pilot survey dala Perencanaan Strategis } \\
\text { SI, Laporan Akhir Penelitian dan Artikel Penelitian }\end{array}$ \\
\hline
\end{tabular}

Dari hasil analisis dengan menggunakan alat-alat seperti CSF, analisis value chain, Gap Analisis, portofolio McFarlan, akan menghasilkan rekomendasi strategi sebagai berikut :

a) Strategi Manajemen SI/TI: Strategi Manajemen SI/TI pada suatu perusahaan didapatkan dari hasil analisis perencanaan strategis sistem informasi berupa kebijakan organisasi dalam menerapkan strategi SI/TI sesuai kondisi manajemen pada perusahaan tersebut.

b) Strategi Sistem Informasi Bisnis : Strategi sistem informasi bisnis yang dihasilkan dapat mendukung bisnis perusahaaan. Strategi ini dihasilkan dari analisis dengan berbagai alat.

c) Strategi Teknologi Informasi : Strategi TI pada perusahaan yang diturunkan dan dihasilkan dari perencanaan strategis berupa arahan pengembangan teknologi.

Dengan adanya Perencanaan Strategis SI/TI yang baik, maka diharapkan dapat membantu dalam menentukan strategistrategi yang tepat untuk mencapai visi, misi Politeknik Negeri Bandung

\section{HASIL DAN PEMBAHASAN}

Analisis dan interpretasi data dan informasi dilakukan untuk memberikan pemahaman terhadap kondisi eksisting perusahaan saat ini dan faktor-faktor yang mempengaruhinya. Dengan pemahaman yang baik, maka diharapkan perencanaan strategis yang disusun dalam membantu perusahaan mencapai tujuan, serta visi dan misi organisasi. Agar dapat menentukan kebutuhan bisnis dan informasi yang akurat, maka dibutuhkan pemahaman yang mendalam terhadap kondisi lingkungan perusahaan, dengan melakukan analisis lingkungan internal maupun lingkungan eksternal perusahaan. Analisis dilakukan pada lingkungan internal bisnis dan SI/TI maupun lingkungan eksternal bisnis dan SI.

\subsection{Analisis Critical Success Factor}

Berdasarkan hasil wawancara dengan Polban dan dengan menganalisis dokumen-dokumen yang berhubungan dengan strategi bisnis organisasi Politeknik Negeri Bandung, dapat diidentifikasi tujuan utama Polban dari Renstra Polban 2020-2024. 


\begin{tabular}{|c|c|c|c|}
\hline No & Indikator Kinerja Tujuan & Satuan & Target \\
\hline 1 & Rata-rata predikat SAKIP minimal BB & Predikat & A \\
\hline 2 & Rata-rata nilai kinerja anggaran atas pelaksanaan $\mathrm{RKA}-\mathrm{KL}$ & nilai & 98 \\
\hline 3 & $\begin{array}{l}\text { Persentase lulusan S2/D4/D3 yang berhasil bekerja sesuai } \\
\text { dengan bidangnya/melanjutkan studi/wiraswasta }\end{array}$ & $\%$ & 85 \\
\hline 4 & $\begin{array}{l}\text { Persentase lulusan } \mathrm{SI} \text { dan } \mathrm{D} 4 / \mathrm{D} 3 / \mathrm{D} 2 \text { yang: menghabiskan } \\
\text { paling sedikit } 20 \text { (dua puluh) sks di luar kampus, atau meraih } \\
\text { prestasi paling rendah tingkat nasional }\end{array}$ & $\%$ & 17 \\
\hline 5 & $\begin{array}{l}\text { Persentase dosen yang berkegiatan tridharma di kampus lain, } \\
\text { di QS100 (berdasarkan ilmu), bekerja sebagai praktisi di } \\
\text { dunia industri, atau membina mahasiswa yang berhasil } \\
\text { meraih prestasi minimal tingkat nasional dalam } 5 \text { tahun } \\
\text { terakhir }\end{array}$ & $\%$ & 18 \\
\hline 6 & $\begin{array}{l}\text { Persentase dosen tetap berkualifikasi akademik } \mathrm{S} 3 \text {; memiliki } \\
\text { sertifikat kompetensi/profesi yang diakui oleh industri dan } \\
\text { dunia kerja; atau berasal dari kalangan praktisi profesional, }\end{array}$ & $\%$ & 80 \\
\hline 7 & $\begin{array}{l}\text { Jumlah keluaran penelitian dan pengabdian kepada } \\
\text { masyarakat y ang berhasil mendapat rekognisi internaional } \\
\text { atau diterapkan oleh masyarakat per jumlah dosen }\end{array}$ & $\%$ & 0.15 \\
\hline 8 & $\begin{array}{l}\text { Persentase program studi S2/D4/D3 yang melaksanakan } \\
\text { kerjasama dengan mitra }\end{array}$ & $\%$ & 40 \\
\hline 9 & $\begin{array}{l}\text { Persentase mata kuliah S2/D4/D3 dan Diploma yang } \\
\text { menggunakan pemecahan kasus (case method) atau project- } \\
\text { based learning sebagai sebagian bobot evaluasi }\end{array}$ & $\%$ & 40 \\
\hline 10 & $\begin{array}{l}\text { Persentase prodi S2/D4/D3 yang memiliki akreditasi atau } \\
\text { sertifikasi internasional yang diakui pemerintah }\end{array}$ & $\%$ & 3.5 \\
\hline
\end{tabular}

Gambar 6. Tujuan Utama Polban

\subsection{Analisis Value Chain Institusi}

Memahami lingkungan bisnis pada Polban, perlu dipahami juga proses bisnis yang berjalan pada internal organisasi Polban. Dengan value chain juga diidentifikasi factor-faktor yang menjadi kesuksesan dalam mengelola perguruan tinggi, value chain juga digunakan untuk menyusum strategi dan menentukan sistem informasi mana yang memberikan nilai lebih terutama dalam mendukung masing-masing aktivitas pada Polban. Berdasarkan value chain, aktivitas internal organisasi dibagi menjadi dua, yaitu aktifitas utama (primary activities) dan aktifitas pendukung (support activities). Dari tahapan ini, seperti gambar 7, terdapat aktivitas utama dan pendukung di Polban.

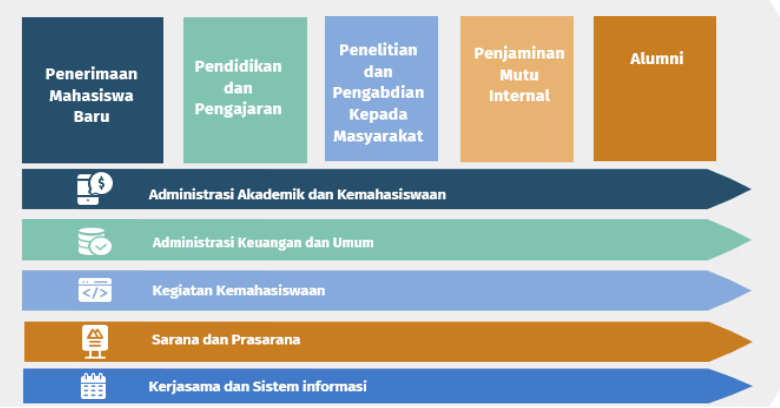

Gambar 7. Hasil analisis Value Chain Polban

Di bawah ini adalah penjelasan dari masing-masing aktivitas utama Polban.

a) Penerimaan Mahasiswa Baru.

b) Pendidikan dan Pengajaran.

c) Penelitian dan Pengabdian kepada Masyarakat.

d) Penjaminan Mutu Internal.

e) Alumni.

Di bawah ini adalah penjelasan dari masing-masing aktivitas pendukung Polban.

a) Administrasi Akademik dan Kemahasiswaan

b) Administrasi Keuangan dan Umum

c) Kegiatan Kemahasiswaan

d) Sarana dan Prasarana 
Building of Informatics, Technology and Science (BITS)

Volume 3, No 3, December 2021, Page 130-140

ISSN 2684-8910 (media cetak)

ISSN 2685-3310 (media online)

DOI 10.47065/bits.v3i3.1013

e) Kerjasama dan Sistem Informasi

Dengan menggambarkan value chain ini, diidentifikasi terdapat system informasi yang digunakan dalam menunjang aktivitas tersebut. Hasil analisis kebutuhan dari rantai nilai informasi ini lalu dipetakan kedalam kondisi eksisting dengan cara menganalisis system eksisting tersebut lalu digunakan dalam melakukan analisis selanjutnya yaitu analisis kesenjangan. Analisis PEST merupakan suatu cara atau alat yang bermanfaat untuk meringkas lingkungan eksternal dalam operasi bisnis. PEST harus ditindaklanjuti dengan pertimbangan bagaimana bisnis harus menghadapi pengaruh dari lingkungan politik, ekonomi, sosial, dan teknologi. Analisis PEST mencakup kondisi lingkungan makro Indonesia, yaitu perekonomian, teknologi, politik dan hukum, dan sosiokultural. Analisis PEST terkait dengan pengaruh lingkungan pada suatu bisnis. Analisis PEST untuk Polban dapat dipaparkan seperti di bawah ini.

Tabel 2. Hasil Analisis PEST

\begin{tabular}{|c|c|}
\hline \multicolumn{2}{|c|}{ Hasil Analisis PEST } \\
\hline Politik & Kebutuhan IS \\
\hline $\begin{array}{l}\text { Undang Undang RI No. } 12 \text { tahun } 2012 \text { tentang } \\
\text { Pendidikan Tinggi }\end{array}$ & $\begin{array}{l}\text { Sistem Informasi Akademik yang terhubung dengan Pangkalan Data } \\
\text { Perguruan Tinggi (Feeder Dikti). }\end{array}$ \\
\hline $\begin{array}{lcccr}\text { Peraturan Pemerintah } & \text { No. } 4 & \text { tahun } & 2014 \\
\text { tentangpenyelenggaraan } & \text { pendidikan } & \text { tinggi } & \text { dan } \\
\text { pengelolaan perguruan } & & & & \end{array}$ & $\begin{array}{l}\text { Learning Management System untuk Pendidikan Jarak Jauh dan } \\
\text { mengadopsi Blended Learning }\end{array}$ \\
\hline Permendikbud No. 109 Tahun 2013 tentang & Penjaminan \\
\hline $\begin{array}{l}\text { Penyelenggaraan Pendidikan Jarak Jauh di Pendidikan } \\
\text { Tinggi }\end{array}$ & $\begin{array}{l}\text { mampumenyajikan informasi yang dapat digunakan untuk } \\
\text { kebutuhan Akreditasi }\end{array}$ \\
\hline $\begin{array}{l}\text { Permendikbud No. } 50 \text { Tahun } 2014 \text { tentang Satuan } \\
\text { Penjaminan Mutu Internal (SPMI) }\end{array}$ & \\
\hline Ekonomi & Kebutuhan IS \\
\hline $\begin{array}{l}\text { Permintaan tenaga kerja terampil vokasi baik D3 dan D4 } \\
\text { meningkat }\end{array}$ & $\begin{array}{l}\text { Sistem informasi terintegrasi untuk pemenuhan lulusan terintegrasi } \\
\text { dengan dunia usaha dan industri }\end{array}$ \\
\hline Sosial & Kebutuhan IS/IT \\
\hline $\begin{array}{l}\text { Dunia Usaha dan Dunia Industri bisa dimanfaatkan } \\
\text { sebagai jembatan dalam mencapai tujuan dan sasaran } \\
\text { institusi }\end{array}$ & Sistem informasi yang menghubungkan dengan dunia industri \\
\hline Beasiswa maupun CSR dari industri bisa dimanfaatkan & $\begin{array}{l}\text { Sistem informasi yang menghubungkan dengan dunia industri dalam } \\
\text { pemanfaatan beasiswa atau CSR }\end{array}$ \\
\hline Teknologi & Kebutuhan IS \\
\hline $\begin{array}{l}\text { Perkembangan teknologi untuk berbagai paltform baik } \\
\text { web, mobile }\end{array}$ & $\begin{array}{l}\text { Sistem informasi yang dikembangkan harus mendukung berbagai } \\
\text { platform }\end{array}$ \\
\hline Internet of Things & Teknologi IoT semakin mudah dikembangkan dan murah \\
\hline Integrasi & $\begin{array}{l}\text { Antas sistem informasi harus mendukung integrasi dengan berbagai } \\
\text { model }\end{array}$ \\
\hline
\end{tabular}

\subsection{Identifikasi Hasil Analisis Solusi}

Hasil analisis pengaruh dari tahapan yang sudah dilakukan yaitu internal bisnis. eksternal bisnis, maka perlu dilakukan identifikasi solusi eksisting terhadap setiap hasil analisis terkait dengan value chain dan indicator kunci dari CSF. Berikut ini adalah hasil identifikasi solusi terhadap hasil analisis:

Tabel 3. Hasil Analisis Solusi

\begin{tabular}{|c|c|c|c|}
\hline No. & Domain & SI & Ruang Lingkup \\
\hline \multirow[t]{4}{*}{1.} & Kerjasama dan & CRM(Customer & Mengelola relasi dan komunikasi dengan sekolah \\
\hline & Sistem & Management) & Mengelola relasi dan komunikasi dunia usaha dan dunia industri \\
\hline & Informasi & & Mengelola relasi dan komunikasi dengan orang tua \\
\hline & & & Mengelola relasi dan komunikasi dengan alumni \\
\hline \multirow[t]{4}{*}{2} & Pendidikan dan & SI Akademik & Mengelola kegiatan akademik, KBM., dan jadwal \\
\hline & Pengajaran & & Mengelola administrasi mahasiswa dalam kegiatan KBM \\
\hline & & & Penerimaan mahasiswa baru \\
\hline & & & Mengelola kegiatan akademik dosen \\
\hline \multirow[t]{2}{*}{3} & Penelitian dan & SI Penelitian dan PkM & Mengelola kegiatan penelitian dosen \\
\hline & PkM & & Mengelola kegiatan pengabdian kepada masyarakat dosen \\
\hline 4. & $\begin{array}{l}\text { Penjaminan } \\
\text { Mutu Internal }\end{array}$ & $\begin{array}{l}\text { SISatuan Penjaminan } \\
\text { Mutu }\end{array}$ & $\begin{array}{l}\text { Berisi informasi terkait penjaminan mutu dan audit internal dari } \\
\text { setiap jurusan dan prodi }\end{array}$ \\
\hline 5. & $\begin{array}{l}\text { Sarana dan } \\
\text { Prasarana }\end{array}$ & E-office & $\begin{array}{l}\text { aplikasi yang mengganti proses administrasi berbasis manual ke } \\
\text { proses berbasis elektronis (paperless), antara lain mengelola } \\
\text { persuratan, nota dinas, tata persuratan,pemantauan surat masuk dan } \\
\text { keluar, Agenda Pimpinan, Disposisi, repository dokumen elektronik }\end{array}$ \\
\hline
\end{tabular}


Building of Informatics, Technology and Science (BITS)

Volume 3, No 3, December 2021, Page 130-140

ISSN 2684-8910 (media cetak)

ISSN 2685-3310 (media online)

DOI 10.47065/bits.v3i3.1013

\begin{tabular}{|c|c|c|c|}
\hline No. & Domain & SI & Ruang Lingkup \\
\hline \multirow[t]{3}{*}{6} & Administrasi & \multirow[t]{3}{*}{ SI Sapra } & Mengelola asset fisik dan non fisik \\
\hline & Keuangan dan & & mengelola bahan habis (stok gudang) dan ATK \\
\hline & Umum & & Mengelola pemasukan keuangan \\
\hline 5 & $\begin{array}{l}\text { Sarana dan } \\
\text { Prasarana }\end{array}$ & SI Pengadaan & $\begin{array}{l}\text { Mengelola pengeluaran keuangan } \\
\text { mengelola pengadaan secara elektronik dengan ruang lingkup non } \\
\text { lelang }\end{array}$ \\
\hline \multirow[t]{2}{*}{6} & & \multirow[t]{2}{*}{ SI Kemahasiswaan } & mengelola kegiatan kemahasiswaan (dapat disatukan dengan SI \\
\hline & $\begin{array}{l}\text { Kemahasiswaa } \\
\text { an }\end{array}$ & & Akademik) \\
\hline \multirow[t]{3}{*}{7} & Sarana dan & \multirow[t]{3}{*}{ SI Perencanaan } & mengelola pengusulan rencana dan pemantauan anggaran. \\
\hline & Prasarana & & Monitoring pelaksanaan kegiatan penggunaan anggaran \\
\hline & & & Evaluasi pelaksanaan kegiatan penggunaan anggaran \\
\hline
\end{tabular}

\subsection{Analisis Kesenjangan}

Berdasarkan hasil dari analisi internal dan eksternal, kemdian dilakukan analisis kesenjangan antara eksisting dengan harapan dari identifikasi solusi system informasi yang ada, selanjutnya dapat dipetakan kesenjangan dan aksi yang akan dilakukan. Hasil analisis kesenjangan seperti tabel 4 untuk SI yang perlu dikembangkan dengan menentukan ruang lingkup dari setiap SI dan dalam McFarlan Portfolio, dibawah ini ditampilkan kesenjangan yang medium dan tinggi, yaitu domain pendidikan dan pengajaran lalu penelitian dan pengabdian kepada masyarakat .

Tabel 4. Analisis Kesenjangan

\begin{tabular}{|c|c|c|c|c|}
\hline Problem domain & Current State & Gap & Action Plan & Prioritas \\
\hline $\begin{array}{l}\text { Pendidikan dan } \\
\text { Pengajaran }\end{array}$ & $\begin{array}{l}\text { Sistem yang sudah ada ada } \\
\text { sudah terbangun dengan } \\
\text { baik dan terintgrasi dengan } \\
\text { feeder dikti. } \\
\text { LMS sudah berjalan, tapi } \\
\text { tidak semua fitur bisa } \\
\text { digunakan. }\end{array}$ & $\begin{array}{lr}\text { Tidak adanya dokumen } \\
\text { bisnis proses } \\
\text { Dengan adanya sister } \\
\text { feeder dikti terbaru yang } \\
\text { mengadopsi Merdeka } \\
\text { Belajar, system akademik } \\
\text { harus menyesuaikan } \\
\text { kembali } \\
\text { LMS harus bisa } \\
\text { menyesuaikan dengan } \\
\text { metode blended learning. }\end{array}$ & $\begin{array}{l}\text { Membuat dokumen } \\
\text { bisnis proses } \\
\text { Mengintegrasikan } \\
\text { dengan feeder dikti } \\
\text { terbaru seusia dengan } \\
\text { MBKM } \\
\text { Mengimplemntasikan } \\
\text { fitur di LMS untuk } \\
\text { Blended Learning }\end{array}$ & High \\
\hline $\begin{array}{l}\text { Penelitian } \\
\text { PkM }\end{array}$ & $\begin{array}{l}\text { Sistem penelitian dan pkm } \\
\text { sudah ada yaitu SIPPM } \\
\text { Sistem saat ini Sebagian } \\
\text { terintegrasi dengan SIPAK }\end{array}$ & $\begin{array}{l}\begin{array}{l}\text { 1. Belum terintegrasi } \\
\text { dengan ekternal }\end{array} \\
\text { stakeholder seperti Sister } \\
\text { Polban dan Simlibtabmas }\end{array}$ & $\begin{array}{l}\text { 1. Melengkapi bisnis } \\
\text { proses sippm terkait } \\
\text { tridarma penelitian dan } \\
\text { PkM } \\
\text { 2. Integrasi dengan } \\
\text { Sister, Siblibtabmas }\end{array}$ & Medium \\
\hline
\end{tabular}

\subsection{McFarlan Portfolio Smart Campus}

McFarlan Portfolio digunakan untuk memetakan aplikasi SI berdasarkan kontribus terhadap organisasi dari hasil kuesioner dengan skala prioritas menggunakan metode USG. Hasil pemetaan dilakukan sesuia dengan empat kuadran (strategic, high potential, key operation, and support) pada McFarlan Portfolio. Dengan skor USG yang paling tinggi ke kuadran High Potential dan selanjutnya diidentifikasi SI yang lebih cocok ke kuadran support. Dari hasil pemetaan tersebut didapat gambaran kontribusi sebuah aplikasi SI terhadap organisasi dan pengembangan dimasa mendatang, keempat kuadran tersebut dapat dilihat pada gambar dibawah ini.

\begin{tabular}{|c|c|c|c|c|c|c|c|c|}
\hline \multirow[t]{2}{*}{ No } & \multirow[t]{2}{*}{ SI } & \multirow[t]{2}{*}{ Ruang Lingkup } & \multicolumn{3}{|c|}{ Frekuensi } & \multirow{2}{*}{$\begin{array}{c}\text { Respond } \\
\text { en }\end{array}$} & \multirow[b]{2}{*}{ Skor } & \multirow{2}{*}{$\begin{array}{c}\text { Rata-rata } \\
\text { per SI }\end{array}$} \\
\hline & & & $\mathbf{U}$ & $\mathbf{S}$ & $\mathbf{G}$ & & & \\
\hline \multirow[t]{5}{*}{1.} & \multirow[t]{5}{*}{ Akademik } & Mengelola kegiatan KBM & 5 & 2 & 4 & 11 & 21 & 3,67 \\
\hline & & $\begin{array}{l}\text { Mengelola kegiatan ekstra kurikule (disatukan dr kegiatan } \\
\text { kemahasicwaan) }\end{array}$ & 3 & 3 & 4 & 10 & 21 & 3,33 \\
\hline & & Mengelola kegiatan ko-kurikuler & 2 & 3 & 0 & 5 & 8 & 1,67 \\
\hline & & Operasional Akademik Mahasiswa dan dosen & 4 & 4 & 2 & 10 & 18 & 3,33 \\
\hline & & Mengelola beasiswa mahasiswa & 4 & 4 & 4 & 12 & 24 & 4,00 \\
\hline \multirow[t]{5}{*}{2.} & \multirow{5}{*}{ Kepegawaian } & Mengelola data-data pegawai & 4 & 3 & 3 & 10 & 19 & 3,33 \\
\hline & & Mengelola kehadiran pegawai & 4 & 4 & 4 & 12 & 24 & 4,00 \\
\hline & & Mengelola kinerja pegawai & 4 & 3 & 3 & 10 & 19 & 3,33 \\
\hline & & Mengelola beasis wa pegawai & 4 & 4 & 3 & 11 & 21 & 3,67 \\
\hline & & Integrasi dengan BKD dan SKP & 4 & 4 & 4 & 12 & 24 & 4,00 \\
\hline
\end{tabular}

Gambar 8a. Penentuan prioritas untuk integrasi dan/atau penambahan fasilitas pada SI yang sudah ada. 
Building of Informatics, Technology and Science (BITS)

Volume 3, No 3, December 2021, Page 130-140

ISSN 2684-8910 (media cetak)

ISSN 2685-3310 (media online)

DOI 10.47065/bits.v3i3.1013

\begin{tabular}{|c|c|c|c|c|c|c|c|c|}
\hline \multirow[t]{4}{*}{3} & \multirow[t]{4}{*}{ Penelitian dan PkM } & Mengelola tugas akhir mahasiswa & 1 & 3 & 3 & 7 & 16 & 2,33 \\
\hline & & Mengelola publikasi ilmiah dosen dan mahasiswa & 4 & 3 & 3 & 10 & 19 & 3,33 \\
\hline & & integrasi penelitian dosen dengan simlibtabmas dan pkm belmawa & 3 & 3 & 4 & 10 & 21 & 3,33 \\
\hline & & Mengelola jurnal di lingkungan institusi & 3 & 3 & 3 & 9 & 18 & 3,00 \\
\hline \multirow[t]{2}{*}{4} & \multirow[t]{2}{*}{ Karir dan Alumni } & $\begin{array}{l}\text { Mengelola kegiatan perekrutan mahasiswa dan/atau alumni untuk } \\
\text { hekeria }\end{array}$ & 0 & 4 & 1 & 5 & 11 & 1,67 \\
\hline & & Mengelola data alumni & 4 & 2 & 4 & 10 & 20 & 3,33 \\
\hline 5 & Dashboard Executive & Dashboard untuk Eksekutif & 4 & 4 & 5 & 13 & 27 & 4,33 \\
\hline 6 & $\begin{array}{l}\text { Learning Management } \\
\text { System }\end{array}$ & E-Learning dan Pengelolaan kegiatan KBM Blended Learning & 4 & 5 & 5 & 14 & 29 & 4,67 \\
\hline
\end{tabular}

Gambar 8b. Penentuan prioritas untuk integrasi dan/atau penambahan fasilitas pada SI yang sudah ada.

Hasil pemetaan menggunakan McFarlan Portfolio dibuat berdasarkan analisis di lingkungan bisnis serta analisis internal dan eksternal lingkungan sistem informasi eksisting dari POLBAN. Dalam menentukan kebutuhan system informasi pada Polban didapatkan dari hasil metrics kondisi eksisting internal dan eksternal Polban kemudian dipetakan McFarlan Strategic Grid yang terlihat pada Gambar 9.

\begin{tabular}{|l|l|}
\hline STRATEGIC & HIGH POTENTIAL \\
\hline EIS / Dashboard & SI Akademik \\
Karir dan Alumni & SI Penjaminan Mutu \\
& SI Penelitian dan PkM \\
& Learning Management System \\
\hline KEY OPERATIONAL & SUPPORT \\
\hline SI Akademik & SI Perustakaan Official Website e- \\
SI Kepegawaian & office \\
SI Keuangan & \\
SI SAPRA & \\
SI Pengadaan & \\
Learning Management System & \\
\hline
\end{tabular}

\section{Gambar 9. McFarlan Portfolio}

Dalam portofolio tersebut aplikasi dikategorikan ke dalam empat kategori yaitu key operational, aplikasi yang nantinya akan dipakai dan bermanfaat untuk menopang kegiatan operasional suatu bisnis pada Polban. Kuadran selanjutnya adalah support, yang merupakan aplikasi pendukung yang dapat menciptakan keunggulan tersendiri namun keberadaannya tidak menjadi suatu hal yang pentinf dalam mendukung proses bisnis atau memberikan keuntungan kompetitif bagi Polban. Berikutnya adalah kategori strategic yaitu aplikasi yang secara strategis sangat penting dan menopang untuk mendukung kesuksesan bisnis Polban di masa yang akan datang. Kategori yang terakhir adalah high potential merupakan aplikasi inovatif eksisting yang mungkin nantinya akan menjadi sangat penting dalam kebutuhan bisnis pada Polban di masa mendatang seperti dalam Smart Campus

\section{KESIMPULAN}

POLBAN sebagai perguruan tinggi negeri vokasi negeri diharapkan mempunyai rencana strategis system informasi terutama dalam mengimplementasikan Smart Campus yang selaras dengan rencana strategis institusi. Berdasarkan hasil penelitian dapat diambil kesimpulan bahwa penelitian yang telah dilakukan adalah tahap analisis preliminary, karena keterbatasan waktu dan partisipan survei sehingga menghasilkan informasi bagi tahapan selanjutnya. Keterlanjutan penelitian masih dilakukan dengan mengupayakan semua observasi dari setiap stakeholder sivitas akademika,dengan harapan hasil rekomendasi perencanaan strategis SI yang lengkap dalam mengembangkan Smart Campus. Solusi SI yang dihasilkan belum sepenuhnya diselaraskan dengan rencana strategis POLBAN, karena draft Renstra saat inipun masih direvisi. Berdasarkan hasil wawancara dan observasi internal dengan responden PSI menunjukan hasil bahwa tingkat kebutuhan dari organisasi dan manejemen selaku pengambilan keputusan membutuhkan solusi SI dengan ditandai dengan sebagian besar jawaban berada pada medium dan high dan prioritas di level urgent dan growth.

\section{REFERENCES}

[1] S. Du, F. Meng, and B. Gao, "Research on the application system of smart campus in the context of smart city," 2017, doi: 
10.1109/ITME.2016.0166.

[2] W. Muhamad, N. B. Kurniawan, S. Suhardi, and S. Yazid, "Smart campus features, technologies, and applications: A systematic literature review," 2017, doi: 10.1109/ICITSI.2017.8267975.

[3] M. Cordiaz, "Penerapan Smart Campus sebagai Pendukung Kegiatan Pendidikan dalam Tri Dharma Perguruan Tinggi," J. Inform. Univ. Pamulang, 2017, doi: 10.32493/informatika.v2i2.1508.

[4] R. R. Rerung and Y. R. Ramadhan, "Rancang Bangun Sistem Informasi Akademik Dalam Penerapan Smart Campus Untuk Meningkatkan Pelayanan Akademik," JTERA (Jurnal Teknol. Rekayasa), vol. 3, no. 2, p. 191, 2018, doi: 10.31544/jtera.v3.i2.2018.191-210.

[5] J. Peppard and J. Ward, "Beyond strategic information systems: towards an IS capability," J. Strateg. Inf. Syst., vol. 13, no. 2, pp. 167-194, Jul. 2004, doi: 10.1016/j.jsis.2004.02.002.

[6] J. Peppard and J. Ward, "The strategic management of information systems. Building a digital strategy.," in The strategic management of information systems: Building a digital strategy, 2016.

[7] O. Juwita and F. N. Arifin, "Design of information system development strategy based on the conditions of the organization," Proc. 2017 4th Int. Conf. Comput. Appl. Inf. Process. Technol. CAIPT 2017, vol. 2018-Janua, pp. 1-5, 2018, doi: 10.1109/CAIPT.2017.8320732.

[8] J. Yang, N. K. Y. Leung, and B. Young, "The Relationship Between Strategic Information Systems Planning (SISP) and Facilitators to Achieve Successful Business Outcomes in South Korean Organizations," Electron. J. Inf. Syst. Eval., 2020, doi: 10.34190/ejise.20.23.1.009.

[9] A. D. Irfan Nur Arifani, "Perencanaan Strategis Sistem Informasi Dan Teknologi Informasi Pendidik Dan Tenaga Kependidikan," J. Teknol. Inf. Magister Darmajaya, vol. 02, no. 01, pp. 41-51, 2016.

[10] S. Syidada and E. Wahyuningtyas, "Identifikasi Kebutuhan Bisnis Dengan Value Chain Untuk Perancangan Smart Campus Pada Perguruan Tinggi Swasta," J. Ilm. Teknol. Inf. dan Robot., vol. 1, no. 2, pp. 27-34, 2019, doi: 10.33005/jifti.v1i2.20.

[11] P. Widyaningsih, M. Mustafid, and A. F. Rochim, "Perencanaan Strategis Sistem Informasi Pada Institusi Pendidikan Tinggi Menggunakan Analisis Critical Success Factors," J. Sist. Inf. Bisnis, vol. 1, no. 2, pp. 86-92, 2014, doi: 10.21456/vol1iss2pp86-92.

[12] O. Juwita et al., "Governance and management," J. Bus. Res., vol. 2018-Janua, no. 2, pp. 161-166, 2017, doi: $10.2307 / 25148625$.

[13] D. Budiyanto and D. B. Setyohadi, "Strategic information system plan for the implementation of information technology at Polytechnic 'API' Yogyakarta," 2017 5th Int. Conf. Cyber IT Serv. Manag. CITSM 2017, 2017, doi: 10.1109/CITSM.2017.8089267. 